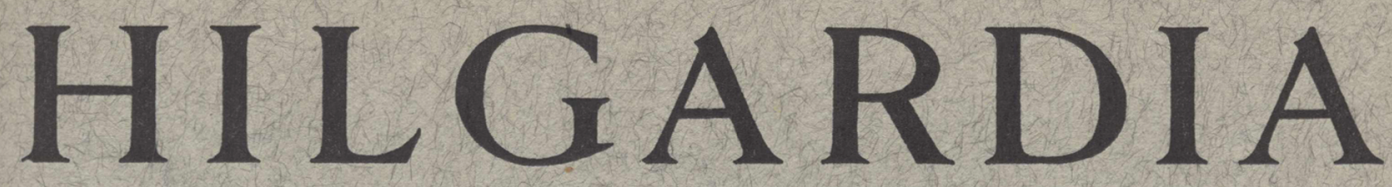

A Journal of Agricultural Science Publisbed by the California Agricultural Experiment Station

\title{
A TECHNIQUE FOR EMBRYO CULTURE OF PEACHES
}

\author{
A. E. CILMORE
}

UNIVERSITY OF CALIFORNIA - BERKELEY, CALIFORINIA 
This publication describes a technique.... for growing peach-embryo cultures. In laboratory experiments, a high percentage of the cultures was free of microorganisms that would develop under yeastextract broth within 15 days at room temperature.

The salient feature of the technique is a "sterilization" procedure on dry, dormant peach seeds, followed by maintenance of aseptic conditions during the subsequent after-ripening. Merthiolate 1:2,000 in 50 per cent alcohol was found to be suitable for the purpose.

Various factors influencing the growth of peachembryo cultures are discussed. Suggestions are also made for establishing a standard practice in growing peachembryo cultures to be used for biological testing. 


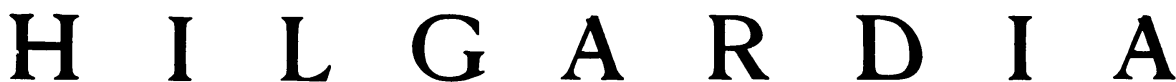

A Journal of Agricultural Science Published by

the California Agricultural Experiment Station

VoI. 20

SEPTEMBER, 1950

No. 8

\section{A TECHNIQUE FOR EMBRYO CULTURE OF PEACHES}

\section{A. E. GILMORE ${ }^{2}$}

IN CONNECTION with investigations on the peach-replant problem (Proebsting and Gilmore, 1941), ${ }^{3}$ a rapid survey method has long been needed for use in testing the effects of peach roots, chemical fractions of peach roots, and other substances on the growth of peach seedlings.

Embryo culture was thought to offer a solution of the problem. Accordingly, in 1941, work was undertaken to develop an embryo-culture technique for the purpose of evaluating the effects of various additions to the culture medium upon the growth of peach seedlings. After somewhat less than a year, the work was of necessity discontinued but was resumed in 1946 .

In the first trials at growing cultures, seeds were after-ripened in moist sand by the usual methods. They were placed in test tubes $25 \times 200 \mathrm{~mm}$, containing about 20 ec of an agar-nutrient medium. They grew and developed into seedlings with well-developed root systems and with plumules up to $13 \mathrm{~cm}$ in length, requiring 14 to 20 days. Response in the type of root development-and possibly in the amount of plumule growth - to substances included in the medium is shown in figure 1 . These cultures were variable, however, and badly infected. Seedlings showed marked tip dieback of the plumule and were in general unsuitable for use in extensive routine testing. The cultures did indicate, however, that response to test substances could be obtained in a relatively short time and offered the distinct advantage that the development of the root system could be observed.

It was considered that the two major requisites of cultures used for testing should be: (1) that the cultures be free from microorganisms and (2) that the cultures be established from seeds that had suffered minimal injury from the means employed to render them sterile and suitable for use.

Attempts were made to produce sterile cultures of seeds taken from pits statified in moist sand by the usual methods. Those showing activity-that is, seeds from which a short radicle had started to grow-were treated with Wilson's (1915) hypochlorite solution, as described by Tukey $(1934,1944)$.

1 Received for publication February 23, 1950.

2 Assistant Specialist in the Experiment Station.

"See "Literature Cited" for citations referred to in text by author and date. 
Sterile cultures were not obtained, however, and the seeds appeared to have been severely injured by the hypochlorite treatment. Actively growing radicles turned brown during any immersion period exceeding 1 minute, and many failed to grow after treatment.

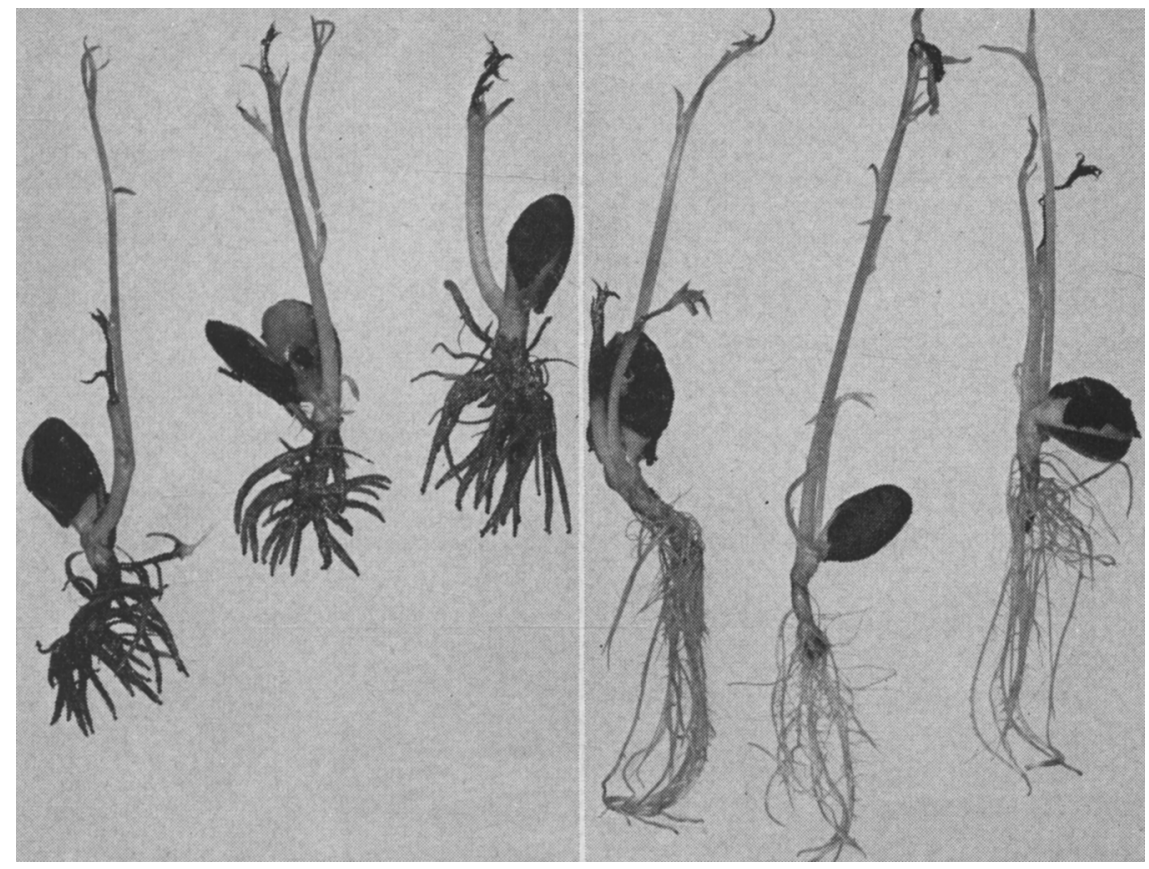

Fig. 1. Response of peach embryos to culture media. (Left) Cultures grown in an agar medium to which a root extract had been added. (Right) Check cultures. Note severe tip dieback of plumules.

\section{EXPERIMENTS WITH DISINFECTANTS}

Treatment of After-ripened Seeds. Table 1 outlines the results of a group of survey experiments performed in the search for a suitable disinfectant for after-ripened peach seeds. After-ripened seeds were used from which radicles were growing. Immersion times in the solutions were variable, ranging from 15 minutes to 2 hours. After treatment, seeds were either cultured on agar or left in moist petri dishes for a few days. Infections were recognized by the development of visible colonies on the seeds. In only two instances (experiments 6 and 32) were seeds free of visible colonies of microorganisms secured, and in both cases the seeds were killed.

There appeared to be two outstanding faults in treating after-ripened seeds. (1) The active tissues were susceptible to injury by the disinfectants used; and (2) it was doubtful whether the disinfectant had access to all organisms, some of which may have penetrated below the surface of the tissues during the after-ripening process.

Treatment of Dormant Seeds. Attempts were next made to sterilize dry dormant seeds. It seemed probable that with properly collected seeds, organ- 
TABLE 1

REACTIONS OF AFTER-RIPENED SEEDS TO VARIOUS DISINFECTANTS Contact times : 15 minutes to 2 hours

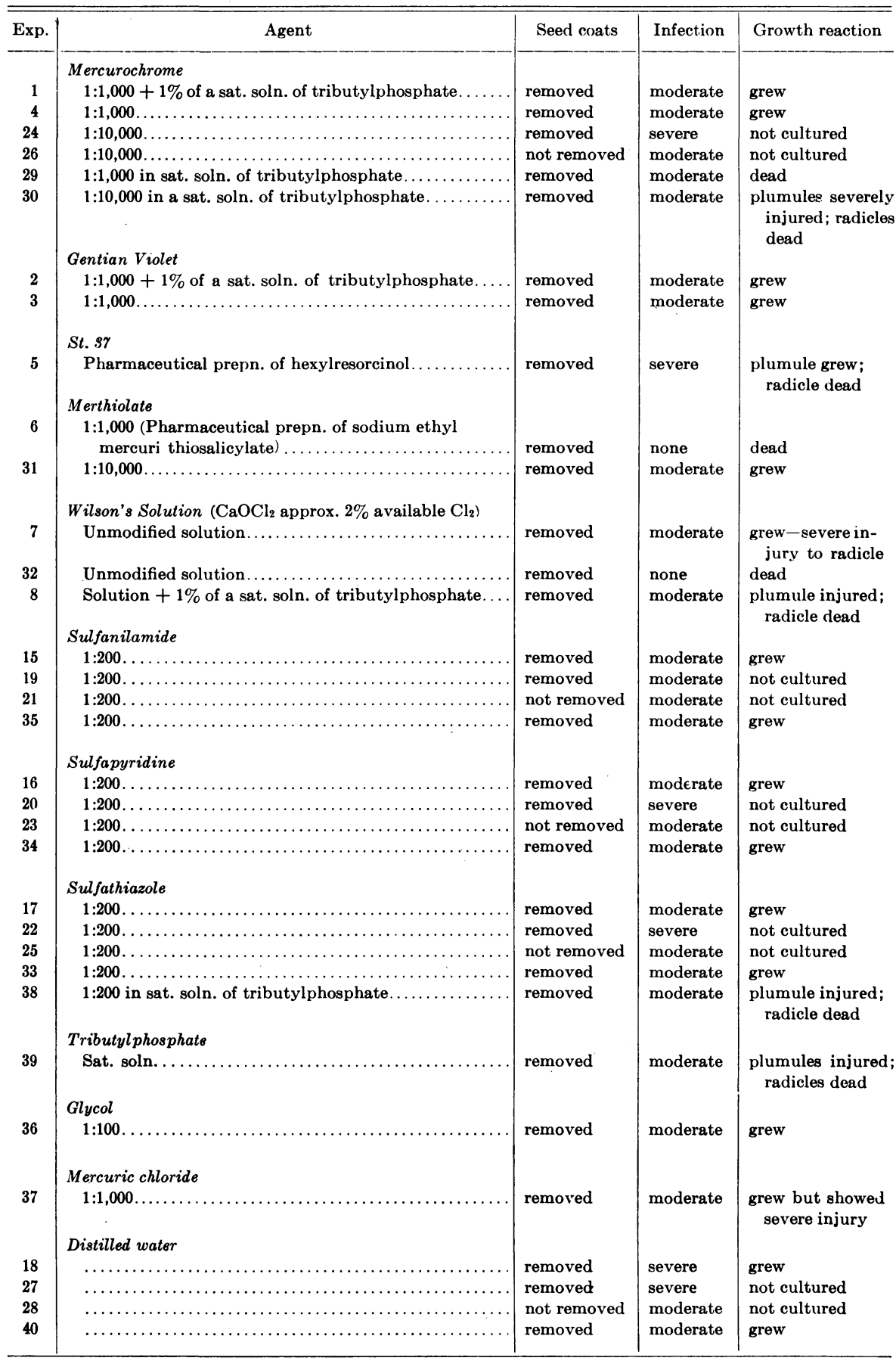


isms would not have penetrated the seed coats and that the seed coats would prevent contact of the disinfectant with the living tissues of the seeds. After disinfection, the seeds were washed and after-ripened under aseptic conditions. Contact time of the disinfectant was accurately controlled at 5 minutes. When Aerosol OT was used as a prewash, the contact time of the prewash was only of sufficient duration to wet the seed coats.

TABLE 2

REACTIONS OF DRY DORMANT SEEDS TO VARIOUS DISINFECTANTS

Contact time: 5 minutes

\begin{tabular}{|c|c|c|c|}
\hline Exp. & Agent & Infection & Growth reaction \\
\hline & Gentian Violet & & \\
\hline 41 & $1: 2,000 \ldots \ldots$ & Severe & Good germination \\
\hline 42 & $1: 20,000 \ldots \ldots \ldots \ldots \ldots \ldots$ & Moderate & Good germination \\
\hline 43 & $1: 2,000$ in $50 \%$ alcohol $\ldots \ldots \ldots \ldots \ldots \ldots \ldots$ & Severe & Good germination \\
\hline 44 & $1: 20,000$ in $50 \%$ alcohol $\ldots \ldots \ldots \ldots \ldots \ldots \ldots$ & Moderate & Good germination \\
\hline 45 & 1:2,000 following Aerosol OT ( $1 \%$ ) prewash........ & Severe & Good germination \\
\hline 46 & $1: 20,000$ following Aerosol OT ( $1 \%)$ prewash....... & Severe & Good germination \\
\hline \multirow[t]{2}{*}{55} & $1: 1,000$ following $24 \mathrm{hr}$. soak in dist. water. $\ldots \ldots \ldots$ & Severe & Poor germination \\
\hline & Merthiolate & & \\
\hline 47 & $1: 2,000 \ldots$ & None & Did not germinate \\
\hline 48 & $1: 20,000$ & Severe & Good germination \\
\hline 49 & $1: 2,000$ in $50 \%$ alcohol. . & None & Excellent germination \\
\hline 50 & $1: 20,000$ in $50 \%$ alcohol. & Slight & Excellent germination \\
\hline 51 & 1:2,000 following Aerosol OT ( $1 \%)$ prewash... & Severe & Good germination \\
\hline \multirow[t]{2}{*}{52} & $1: 20,000$ following Aerosol OT $(1 \%)$ prewash......... & Severe & Good germination \\
\hline & Alcohol & & \\
\hline \multirow[t]{2}{*}{53} & $50 \%$ & Moderate & Poor germination \\
\hline & Aerosol OT & & \\
\hline \multirow[t]{2}{*}{54} & $1 \% \ldots \ldots \ldots \ldots \ldots$ & Severe & Poor germination \\
\hline & Mercurochrome & & \\
\hline 56 & $1: 2,000 \ldots \ldots$ & Severe & Poor germination \\
\hline 57 & [........................... & Severe & Good germination \\
\hline 58 & 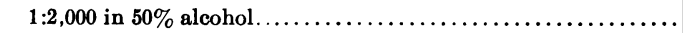 & Slight & Poor germination \\
\hline 59 & $1: 20,000$ in $50 \%$ alcohol $\ldots \ldots \ldots \ldots \ldots \ldots \ldots \ldots \ldots$ & Moderate & Not tested \\
\hline 60 & 1:2,000 following Aerosol OT (1\%) prewash..... & Moderate & Not tested \\
\hline 61 & $1: 20,000$ following Aerosol OT (1\%) prewash................. & Severe & Not tested \\
\hline 62 & $\begin{array}{l}\text { Semisan Bell } \\
\quad 1: 64 \ldots \ldots \ldots \ldots \ldots \ldots\end{array}$ & None & $\begin{array}{l}\text { Excellent germination; } \\
\text { Cotyledons split badly }\end{array}$ \\
\hline
\end{tabular}

Table 2 records this group of experiments. Infection was judged by the development of visible colonies on the seeds during after-ripening or after removal from the cold room. Germination of the seeds was judged in most cases by allowing flasks of after-ripened seeds to stand at room temperature for 24 to 48 hours or, in some cases, by culturing on agar or sand.

Seeds treated with Merthiolate in 1:2,000 dilution in 50 per cent alcohol germinated well and did not develop visible colonies of microorganisms. The failure of the seeds in experiment 47 to grow remains unexplained, as subsequent work with Merthiolate in 1:2,000 dilution with a 5-minute contact 
time has caused no apparent injury to dry seeds. Experiment 62 is the only example of the successful use of Semisan Bell.

Effects of Seed Treatment on the Growth of Cultures. Cultures from seeds treated with Merthiolate-alcohol prior to after-ripening were used as a standard for comparing the effects of various disinfectants upon the growth of the cultures. The results, together with the efficacy of the different disinfectants

\section{TABLE 3}

\section{COMPARISON OF STANDARD MERTHIOLATE AND TREATMENTS WITH} OTHER DISINFECTANTS (25 to 30 seeds were used in each flask)

\begin{tabular}{|c|c|c|c|}
\hline Treatment and contact time & $\begin{array}{l}\text { Number } \\
\text { of flasks } \\
\text { treated }\end{array}$ & $\begin{array}{l}\text { Number } \\
\text { of flasks } \\
\text { infected }\end{array}$ & Comparative vigor of cultures \\
\hline $\begin{array}{l}\text { Merthiolate } 1: 2,000 \text { in } 50 \% \text { alcohol } 5 \text { min. } \\
\quad \text { (standard) } \ldots \ldots \ldots \ldots \ldots \ldots \ldots \ldots \ldots \ldots\end{array}$ & 376 & 2 & $\begin{array}{l}\text { Vigorous: checks against which other } \\
\text { treatments were compared }\end{array}$ \\
\hline Merthiolate $1: 2,000$ in $50 \%$ alcohol $10 \mathrm{~min} . \ldots \ldots$ & 22 & 0 & Slightly less than or equal to check \\
\hline Merthiolate $1: 2,000$ aqueous $5 \min . \ldots \ldots \ldots \ldots$ & 34 & 5 & Equal to check \\
\hline $\begin{array}{l}\text { Merthiolate } 1: 2,000 \text { aqueous } 5 \text { min. following } \\
\text { soaking to wet seed coats. . . . . . . . . . . . . }\end{array}$ & 11 & 1 & Not cultured \\
\hline Merthiolate $1: 2,000$ aqueous $10 \min . \ldots \ldots \ldots$ & 4 & 0 & Slightly less than or equal to check \\
\hline Wilson's Hypochlorite 5 min......... & 4 & 4 & Poor \\
\hline Wilson's Hypochlorite 10 min....... & 1 & 1 & Poor \\
\hline Wilson's Hypochlorite 20 min.... & 1 & 1 & Poor \\
\hline Wilson's Hypochlorite 40 min................ & 1 & 0 & $\begin{array}{l}\text { Grew as well as check culture which in } \\
\text { this case was a poor culture }\end{array}$ \\
\hline Phagon $0.4 \%$ wettable $5 \mathrm{~min}$. & 3 & 3 & Not cultured \\
\hline Phagon $0.4 \%$ wettable not washed from seeds. . & 8 & 0 & Poor: showed discoloration of cotyledons \\
\hline 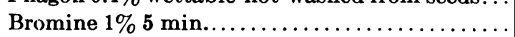 & 4 & 4 & Not cultured \\
\hline 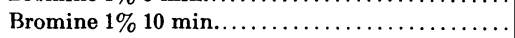 & 3 & 0 & Less vigor than check \\
\hline $\begin{array}{c}\text { Bromine } 20 \text { cc water }+0.1 \text { cc sat. } \mathrm{Br}_{2} \text { solution } \\
\text { not washed from seeds. } \ldots \ldots \ldots \ldots \ldots \ldots \ldots \ldots\end{array}$ & 2 & 2 & Not cultured \\
\hline $\begin{array}{c}\text { Bromine } 20 \text { cc water }+0.2 \text { cc sat. } \mathrm{Br}_{2} \text { solution } \\
\text { not washed from seeds. } \ldots \ldots \ldots \ldots \ldots \ldots \ldots\end{array}$ & 2 & 2 & Not cultured \\
\hline $\begin{array}{c}\text { Bromine } 20 \text { cc water }+0.5 \text { ce sat. } \mathrm{Br}_{2} \text { solution } \\
\text { not washed from seeds. } \ldots \ldots \ldots \ldots \ldots \ldots \ldots \ldots \ldots\end{array}$ & 2 & 0 & Less vigor than check \\
\hline $\begin{array}{l}\text { Bromine } 20 \text { cc water }+1.0 \text { cc sat. } \mathrm{Br}_{2} \text { solution } \\
\text { not washed from seeds. } \ldots \ldots \ldots \ldots \ldots \ldots \ldots \ldots \ldots\end{array}$ & 2 & 0 & Less vigor than check \\
\hline $50 \%$ alcohol $5 \min . \ldots \ldots \ldots \ldots \ldots \ldots \ldots$ & 18 & 8 & Equal to check \\
\hline $50 \%$ alcohol $10 \min . \ldots \ldots \ldots \ldots \ldots \ldots$ & 4 & 1 & Equal to check \\
\hline Semisan Bell 1:64 5 min..................... & 4 & 4 & Not cultured \\
\hline 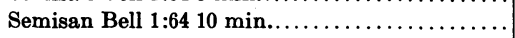 & 4 & 4 & Not cultured \\
\hline Semisan Bell 1:64 not washed from seeds. . & 4 & 0 & Seeds dead \\
\hline Mercuric chloride $1: 2,0005$ min.......... & 2 & 2 & Not cultured \\
\hline $\begin{array}{l}\text { Mercuric chloride } 1: 2,0005 \text { min. following } \\
\text { soaking to wet seed coats................... }\end{array}$ & 12 & 7 & Not cultured \\
\hline Mercuric chloride $1: 2,000$ in $50 \%$ alcohol 5 min... & 2 & 0 & $\begin{array}{l}\text { Slower initial growth than check but } \\
\text { showed less tip dieback }\end{array}$ \\
\hline
\end{tabular}

used in suppressing the growth of organisms, are given in table 3. Of the two infections that occurred in flasks of Merthiolate-alcohol-treated seeds, the closure of one of them is known to have been removed during after-ripening. The criterion of infection in all cases was the presence of visible colonies on the seeds at the time of removal from the after-ripening room or, in the case of Wilson's hypochlorite, with 20-minute contact time (table 3 ), the development of visible colonies in cultures of the seeds. 

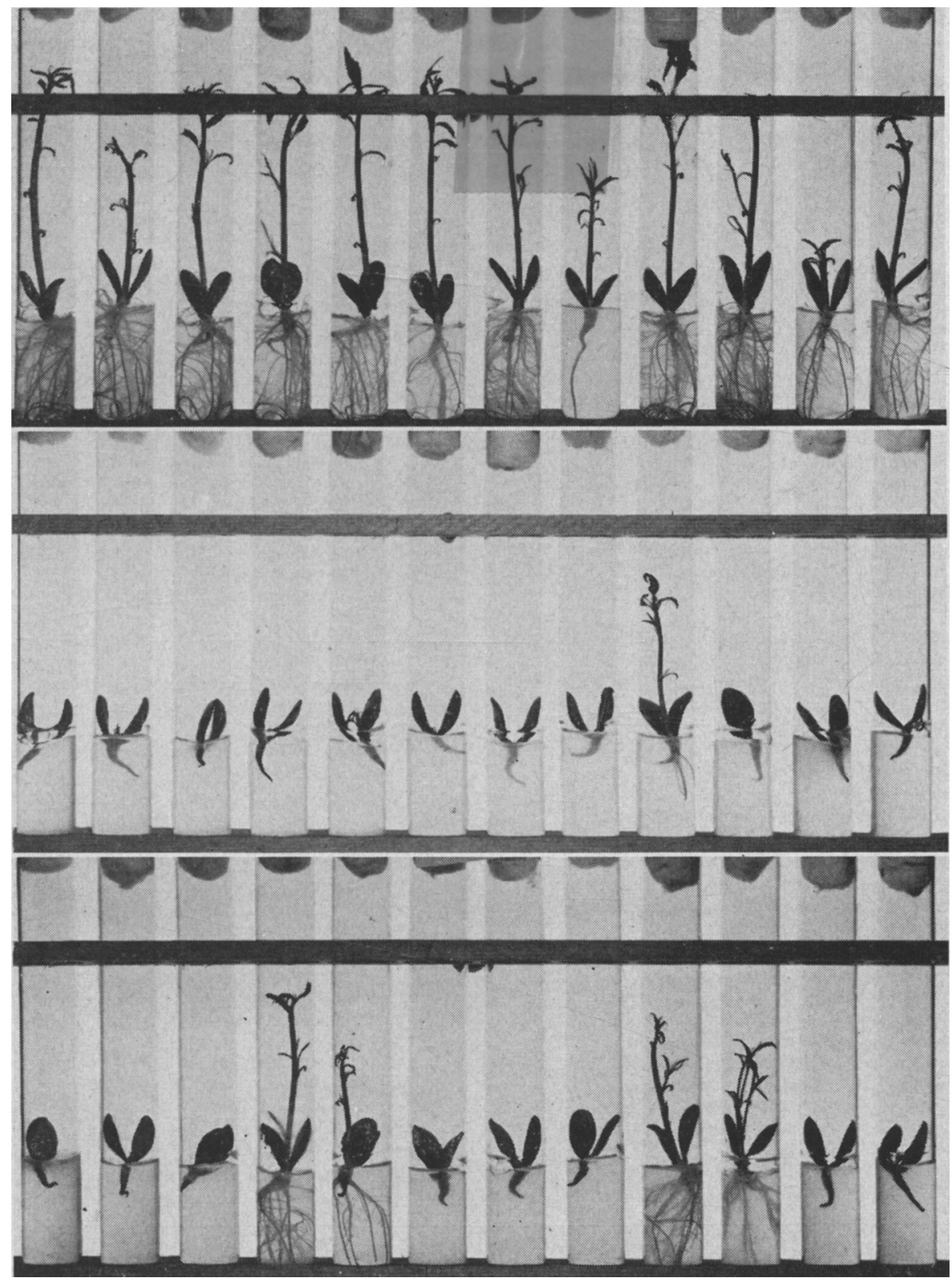

Fig. 2. Toxic reactions of germinated seeds to various disinfectants applied prior to culture. Thirteen-day-old cultures from seeds after-ripened 157 days. (Top) Germinating seeds treated with aqueous Merthiolate 1:2,000 for 5 minutes. (Center) Germinating seeds treated with Wilson's hypochlorite for 5 minutes. (Bottom) Germinating seeds treated with mercuric chloride 1:2,000 for 5 minutes. Wilson's hypochlorite was variable in action and did not always produce as severe injury as shown here. 
Both Merthiolate aqueous $1: 2,000$ and 50 per cent alcohol were fairly satisfactory disinfectants for peach seeds. All factors considered, each was superior to the other substances tried. They produced no apparent injury. The combination of Merthiolate $1: 2,000$ in 50 per cent alcohol was markedly superior to any substance tried. It was quite effective in suppressing the growth of microorganisms and caused no apparent injury to the seeds.

Merthiolate-alcohol is remarkable in its effectiveness against molds, which seem to be the chief infective organisms during after-ripening of the seeds and culture of the embryos. Though, as will be discussed later, some bacteria or their spores escape death during the Merthiolate-alcohol treatment, molds seem to be completely eliminated.

Bromine, as well as mercuric chloride with alcohol, showed promise, as some embryo cultures free of visible growths of infectious and contaminating organisms were obtained from seeds treated with these disinfectants. Both, however, are more injurious to peach seeds than Merthiolate-alcohol.

Relative Toxicity of Merthiolate, Wilson's Hypochlorite, and Mercuric Chloride. Sensitive tests of the relative toxicity of Merthiolate, Wilson's hypochlorite, and mercuric chloride were made by treating actively growing afterripened seeds. Seeds having radicles 1 to $2 \mathrm{~cm}$ long were brought from the cold room and treated for 5 minutes with the disinfectant being tested, washed for 5 minutes, stripped of their seed coats, and cultured on agar. Figure 2 shows comparable cultures of after-ripened seeds treated with 1:2,000 aqueous Merthiolate, Wilson's hypochlorite, and 1:2,000 aqueous mercuric chloride. The aqueous Merthiolate caused less injury than the other sterilants tested.

Experiments with Bromine. Bromine has been successfully used as a seed sterilant by a number of investigators (LaRue, 1937; White, 1943, page 118). In the present work, it was employed in an attempt to eliminate the troublesome details of controlling the time of contact of the disinfectant with the seeds and of washing the seeds after disinfection. It was thought possible to apply sufficient bromine for "sterilization" and yet to keep the amount small enough that all of it would react with the seed coat and be fixed before reaching the living tissues of the seeds, thus leaving them uninjured.

To test this possibility, a number of flasks were set up, each containing 25 seeds and $20 \mathrm{cc}$ of water. Various amounts of bromine water, saturated at room temperature (approximately $20^{\circ} \mathrm{C}$ ), were added (table 3 ). The results indicated that 0.5 to $1.0 \mathrm{cc}$ were about the practical limits of application. These amounts prevented the growth of organisms and the bromine was apparently either taken up by the seed coats or lost through volatilization within 15 to 20 minutes, as shown by the loss of color from the solution. Washing the seeds 1 hour after application of the bromine destroyed its effectiveness and allowed strong colonies of a white mold to develop on the seeds.

Cultures were made of seeds that had been treated with bromine and then after-ripened without washing. The seeds and cultures were apparently free of microorganisms. The cultures grew well during the first few days but soon fell behind the Merthiolate-alcohol-treated checks. Each photograph in figure 3 shows a set of the 12 most vigorous plants selected from a group of 24 . The figure illustrates the differences in maximum, not average, perform- 
ance. The 12 least vigorous cultures from each group showed neither the uniformity nor the marked differences of the sets in the photographs.

Tests of Sterility of Merthiolate-Alcohol Treated Seeds. As the work progressed, hundreds of flasks of seeds were treated with Merthiolate-alcohol. Of the first 376 flasks so treated, only 2 developed visible infections (table 3 ), and one of these was known to have been exposed to contamination.

Large numbers of cultures were grown on inorganic media, and a few were grown for 30 days on a medium containing-in addition to the inorganic salts in the standard medium-glycine, nicotinic acid, pyridoxine, thiamin and sucrose, or glucose. Only a few cultures (except those contaminated by improper handling) developed any visible colonies of microorganisms. As a result of these experiences, Merthiolate-alcohol-treated seeds and cultures grown from them came to be regarded as sterile.

Recently, however, Kester, ${ }^{4}$ using the technique, experienced considerable difficulty with contaminating and infecting organisms in embryo cultures grown on media rich in organic substances, especially those containing yeast extract. His results led to a re-examination of the seeds I had treated. All samples of the after-ripening seeds then in the cold room were found to be contaminated with spore-forming organisms. These organisms could be demonstrated by adding a quantity of 0.5 per cent yeast-extract broth to each flask and incubating the seeds at room temperature for a few days. Most flasks developed vigorous cultures of organisms in 1 to 5 days, but others required incubation periods of 12 to 15 days.

When flasks of seeds were placed under yeast extract soon after treatment with Merthiolate-alcohol, none required more than 25 days' incubation at room temperature to develop strong cultures of microorganisms.

Although several variations in technique and numerous combinations of the disinfectants-crystal violet, mercuric chloride, Merthiolate, and alcohol-were experimented with, no treatment superior to the Merthiolatealcohol treatment was found.

The incubation period for the development of contaminants was markedly increased by treating the seeds with mercuric chloride $1: 2,000$ in 50 per cent alcohol before or after the Merthiolate-alcohol treatment. If the yeast-extract broth was added to the flasks of seeds soon after treatment, incubation times ran from 30 to 146 days, with an average of 100 days. If yeast-extract broth was added after the seeds had been after-ripened, the incubation period averaged 13 days.

It might well be argued that such long incubation periods were the result of contamination during the incubation period, and not of organisms present on the seeds at the time the yeast extract was added. The evidence, however, is that contaminations occurred only infrequently during the incubation periods. In all, 172 flasks of seeds were tested under yeast-extract broth ; only one failed to develop growths of organisms. During these tests, 36 check flasks containing only yeast-extract broth were set up. Only three developed contaminants. One of these was positive soon after the transfer was made and was probably contaminated at that time. The other two developed growth

\footnotetext{
- From unpublished data of Dale E. Kester.
} 

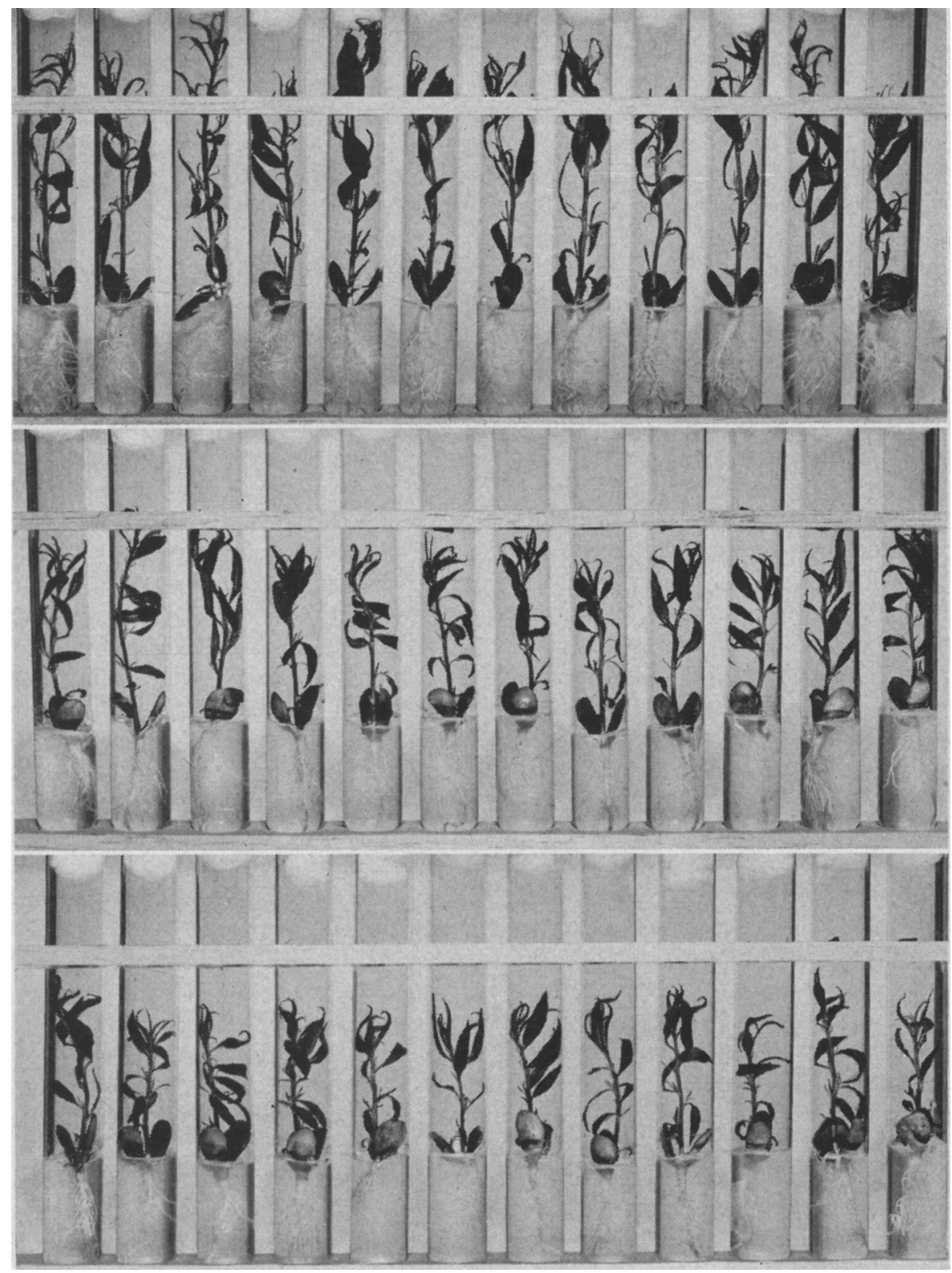

Fig. 3. Comparison of Merthiolate and bromine treatments. Fifteen-day-old cultures from seeds after-ripened 85 days. (Top) From seeds treated, prior to after-ripening, in standard Merthiolate-alcohol mixture. (Center) From seeds treated, prior to after-ripening, by addition of $0.5 \mathrm{cc}$ of bromine water, saturated at $20^{\circ} \mathrm{C}$ to the seed in 20 ec of water. (Bottom) Same treatment as (Center) using $1.0 \mathrm{ce}$ bromine water. Each photo shows the 12 most vigorous cultures from a group of 24 . 
at 64 and 116 days. These were probably contaminated by material passing the closures and may be considered as an index of the rate at which contamination occurred during incubation.

Tests of Sterility of Individual Embryo Cultures. When individual embryo cultures were examined by incubation under yeast-extract broth after the expiration of the 14-day culture period, only 20 out of 204 cultures examined developed colonies of organisms within 14 days. A number of the flasks were checked with yeast-extract broth immediately after the seeds were removed for embryo culture. All showed strong growth of microorganisms, none requiring more than a 7-day incubation period.

Several sets of 12 cultures were grown, none of which showed any contaminants by the yeast-extract-broth test after 15 days. The seeds for these particular sets were taken from the flasks to which yeast-extract broth had been added immediately upon removal of the seeds to be cultured, and in which organisms developed vigorously within 2 to 5 days.

Seed coats were removed before the seeds were cultured. The instruments were wiped with Merthiolate-alcohol and, before they were again sterilized, were used to remove the seed coats from the 12 seeds of a culture set. The establishment of sterile cultures from flasks of contaminated seeds seems to imply that the numbers of organisms were so small that cross contamination between seeds or between seeds and their seed coats occurred infrequently.

Since sterility of the embryo cultures can only be implied by failure to culture out organisms, it can never be said with certainty that an embryo culture is strictly sterile. Screening the cultures by incubating them with yeast-extract broth after the conclusion of the test period seems, however, to be a solution to the problem of establishing a practical criterion or an estimate of the degree of contamination under which the cultures are grown.

Practical Application of Merthiolate-Alcohol to Propagation Practice. The method of "sterilizing" seeds with 1:2,000 Merthiolate in 50 per cent alcohol and after-ripening them under aseptic conditions has been applied by Hesse and Thompson ${ }^{5}$ to the problem of propagating crosses of various species of Prunus. As compared with the usual procedure of after-ripening by stratification in moist sand, significantly increased numbers of seeds were germinated, successfully grown, and transplanted in the field.

The method as used by Hesse differed in two respects from that later described in this paper. (1) The seeds were cultured in nonsterile sand in the greenhouse, and (2) those flasks in which infections occurred during afterripening, were re-treated with $1: 2,000$ aqueous Merthiolate. This practice of re-treating was successful. Infections occurred in their material, because these workers had used many gummy, shrunken, or broken seeds, to which access of the disinfectant was impaired.

\section{MATERIALS AND EQUIPMENT FOR EMBRYO CULTURE}

Seed. Seeds of the Lovell variety were used. The variety is of special interest because it is the most common rootstock for peaches in California.

To avoid the harmful effects of fermentation (Haut and Gardner, 1934; Scott, Waugh, and Cullinan, 1942), the pits were taken directly from the

\footnotetext{
'Personal communication from C. O. Hesse and Lester Thompson.
} 
cutting tables at dry yards. They were placed in heavy wire baskets and cleaned within a few hours by a stream of water from a high pressure spray rig. Sufficient force was used to remove all adhering flesh from the endocarp. The clean pits were then spread in single layers on trays and dried in the shade. The dried pits were cracked in a vise to remove the seeds. These were stored in paper bags at room temperature in the laboratory. They remained viable for at least two years.

Disinfectant. Merthiolate Solution Stainless, 1:1,000 Eli Lilly \& Co., Indianapolis, Indiana, was purchased as a standard pharmaceutical. This was diluted with an equal volume of 95 per cent alcohol to give a $1: 2,000$ dilution of the active agent in approximately 50 per cent alcohol.

Flasks. Flasks for carrying out the seed treatments and after-ripening procedure were 125 ec Erlenmeyers. Each was closed with a 50 or 100 ec beaker, in the bottom of which a cotton pad had been cemented with shellac. This type of closure, suggested by Mudge, ${ }^{\circ}$ offers a considerable advantage over the standard cotton plug with a beaker cover, recommended by White (1943, page 73). The cover and cotton closure can be handled as a unit during all stages of manipulation, and the cotton closure remains protected from contamination. The device is shown beside the larger flask in figure 4.

Sterile Wash Water. Tap water was sterilized and stored in a 6-liter Erlenmeyer flask, closed with a cotton plug, and fitted with a siphon. The delivery end of the siphon terminated with a Pyrex glass or copper tube.

During sterilization and the subsequent storage prior to use, the delivery end of the siphon was protected by enclosure in a small cotton-stoppered Erlenmeyer flask. During sterilization, it was found necessary to support this protective flask on the larger one, as shown in figure 4 . Note that the open end of the delivery tube was held below the level of the liquid in the larger flask, but that the opening of the small protective flask with its cotton stopper was well above the liquid level of the larger one. With this arrangement, the delivery tube usually filled with water during sterilization; it was seldom necessary, therefore, to start the siphon by stripping.

Medium. The medium used for the cultures was a modified Hoagland solu-

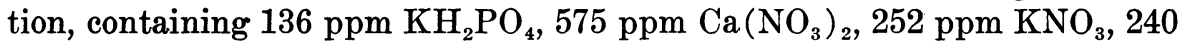
ppm $\mathrm{MgSO}_{4}$, and 1 ce per liter of Hoagland's (1938) solution of minor elements, solidified by the addiiton of 6.5 gms of agar per liter. The agar concentration of the medium, as pointed out by Tukey (1944), is a rather critical factor.

Culture Tubes. Tubes used for the cultures were standard culture tubes $25 \times 200 \mathrm{~mm}$. They were filled to a depth of $50 \mathrm{~mm}$ with the medium, closed with cotton stoppers, and sterilized. Tubes were handled in racks of 12 , each rack constituting a set.

Transfer Chamber. The transfer chamber was a tightly constructed cabinet, 4 feet square by 7 feet high, with sliding glass doors on the front and a series of shelves 10 inches wide, one above the other, the full length of the back. Below these was another shelf 20 inches wide, used as the work table. A 100-cubic-foot-per-minute fan delivered air into the chamber through a 4-inch thickness of oil-soaked, glass-mat filter. In the chamber were a chair,

\footnotetext{
- Personal communication from C. S. Mudge.
} 


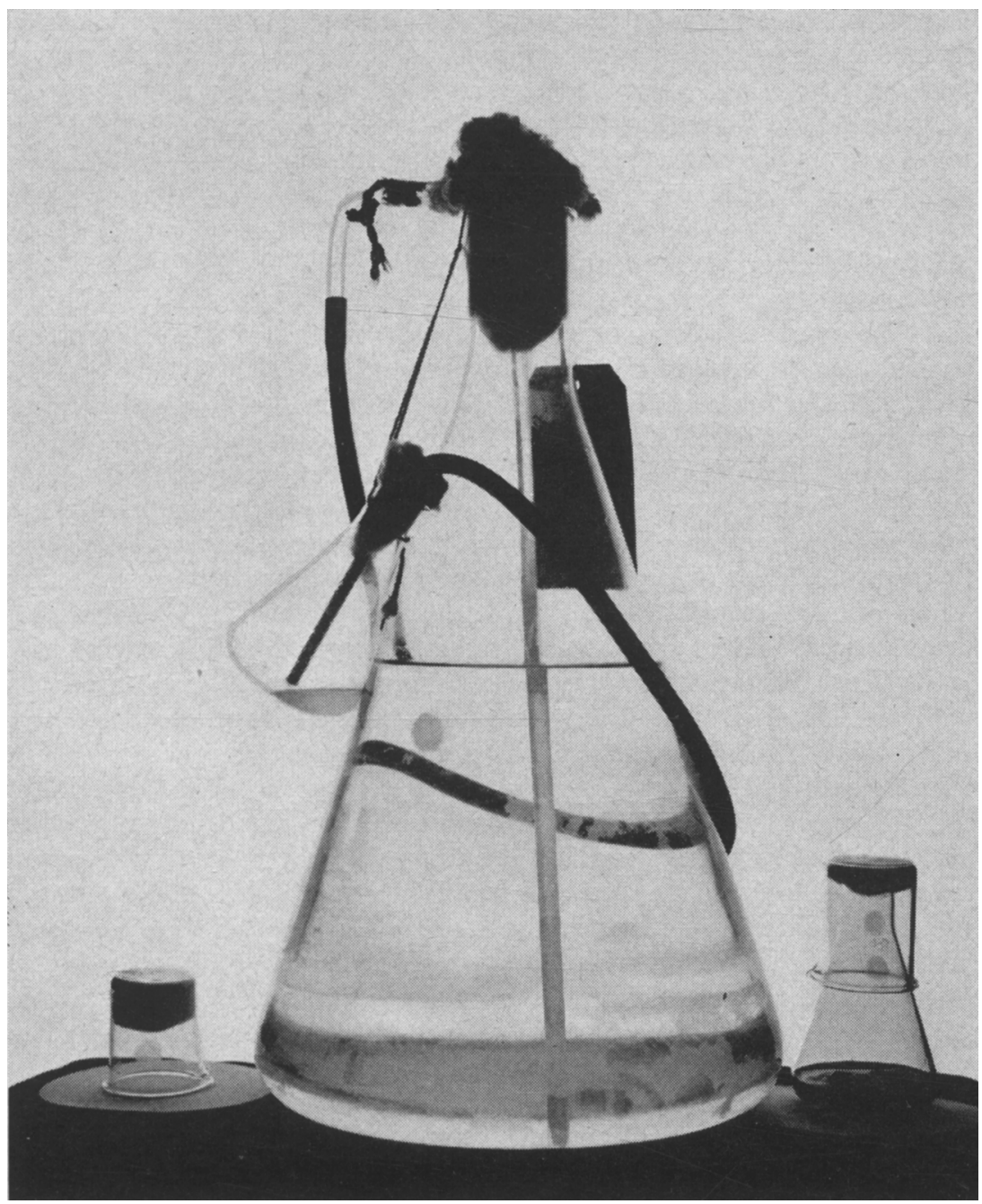

Fig. 4. Center: Flask used for sterilizing and storing the washing and soaking solutions. Left: Closure used on after-ripening flasks. Right: After-ripening flask containing seed with closure in place.

the necessary forceps and scalpels for removing the seed coats of peach seeds, and an alcohol burner.

The chamber was prepared for use by steaming down with a large pressure cooker containing $1 / 2$ to 1 gallon of water, previously heated to a 15 -pound steam pressure. The cooker was placed in a corner, the release cock opened, and the chamber closed. After about 10 minutes, the fan could be turned on, and after an additional 15 or 20 minutes, the operator could enter. 


\section{PROCEDURE FOR PREPARING EMBRYO CULTURES}

Sterilization of Flasks and Treatment of Seeds. The flasks used for treating and after-ripening the seeds were sterilized, with closures in place, in an autoclave. Though the flasks were later contaminated by exposure to the atmosphere of the laboratory and by the nonsterile seeds that were placed in them, sterilization with the closures served two purposes: (1) It was considered desirable to eliminate possible gross infections in the flasks; and (2) sterilization with the closures in place served to fit the cotton pad nicely to the lip of the flask.

Twenty-five to thirty dry seeds, selected for good size, absence of blemishes, and continuity of the seed coat, were placed in each flask. Merthiolate, $1: 2,000$ in 50 per cent alcohol, was poured into one flask to a sufficient depth to cover the seeds. The flask was well shaken to break air bubbles and was left standing uncovered for $4 \frac{1}{2}$ minutes. The Merthiolate solution was then poured to the next flask in the series of not more than 12 flasks. Care was taken to rotate the flask from which the Merthiolate was being poured, so as to wet the entire inner surface and lip. This procedure and flaming the delivery tube of the flask of sterile wash water required $1 / 2$ minute, making the total contact time of the seeds with the disinfectant 5 minutes. The treated seeds and flask were then washed for about 4 minutes with approximately 12 changes of sterile tap water. Washing was done with great care and attention to detail to prevent airborne spores and organisms from falling into the open "sterile" flask. After the disinfectant had been poured from the seeds, the flask was held in a horizontal position and never again turned upright until the neck had been flamed and the closure replaced. An improvement in the procedure would be the use of an accessory closure across the top of the flask during treatment. This would permit wetting the inner surface of the flask at the beginning of the treating period and would protect the contents during treatment.

Figure 5 shows the method of washing. The delivery tube from the sterile water flask was flamed till all water had been boiled out of it. Quickly a little water was run through to cool the tube, which was then introduced into the flask of seeds.

Sterile wash water sufficient to cover the seeds was added. The flask was then shaken and rotated to wash not only the seeds but also the entire inner surface of the flask. As the water was poured off, the sterile tube (through which the wash water had been introduced) was used to prevent escape of the seeds. This process was repeated at least 12 times in the 4-minute washing period.

At the end of the washing period, sufficient sterile water was left in the flask to cover the seeds. The neck of the flask was flamed until dry. Care was taken to hold the flask in an inclined position high in the flame to prevent the introduction of raw illuminating gas from the inner cone of the flame into the atmosphere of the flask. The closure was then put into place immediately.

After-Ripening of the Seeds. After the sterile seeds were soaked at room temperature for 24 hours, most of the water was poured from the flask, only 


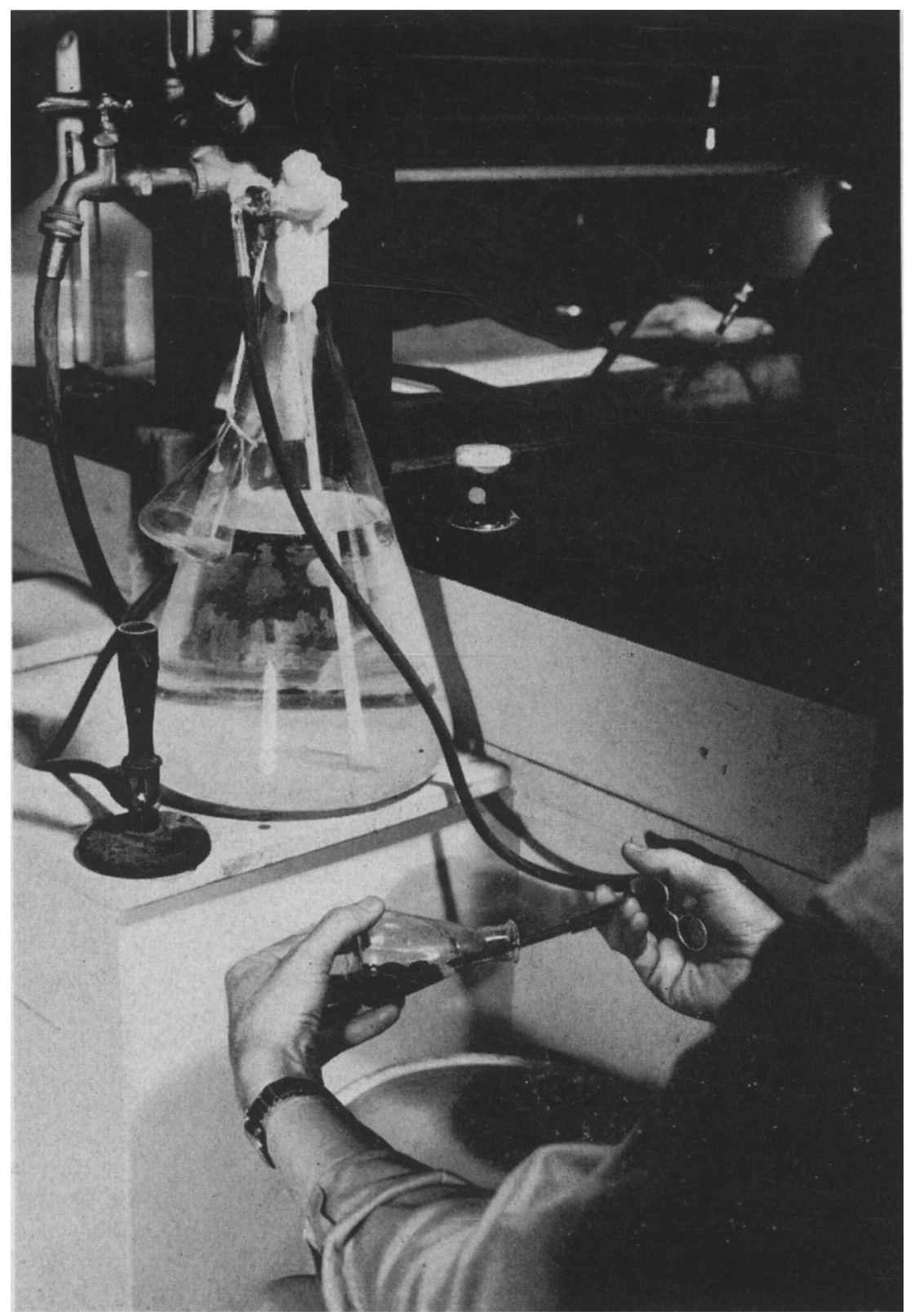

Fig. 5. Illustrating the method of washing the seed after treatment. Note flask held in horizontal position. 
enough being left to half-submerge the seeds in the lower layer. To protect it from contamination during this process, the mouth of the flask was held under the closure. Reflaming was not found necessary at this point. (Now that contaminants are known to be present on the treated seeds, the soaking period is carried out at the after-ripening temperature in order to retard the development of the contaminants.) During the after-ripening in the cold room, the flasks of seeds were carefully watched, and additional sterile water was added before they became dry.

Preparation of the Cultures. Cultures were prepared in the well-steameddown transfer chamber. The instruments were sterilized by wiping with the solution of Merthiolate in 50 per cent alcohol.

A dozen seeds were removed from a flask with the aid of a wire loop and were placed in a petri-dish half. A large forceps was used to hold a seed and a small one with curved points to remove the seed coat. If it had not split during the after-ripening, the seed coat was opened with a scalpel. Though care was taken not to cut deeply, most of the cotyledons were injured to some extent in the process. No effect on the cultures was noted from these slight injuries.

After 12 naked embryos had been collected in a petri-dish half, they were transferred with a long forceps to sterile tubes of agar medium. Care was taken to force the radicles into the medium but to leave the cotyledons above the surface. Lips of the tubes were flamed before reinsertion of the cotton plug.

\section{FACTORS THAT MAY INFLUENCE GROWTH OF CULTURES}

Several factors in the handling of the seeds and cultures may influence the growth of the cultures. In observing these, however, few growth measurements have been made. Sets of cultures-usually evaluated by visual comparison-were classified as inferior or superior to other sets or checks in the same experiment.

Soaking and After-ripening Solutions. Two solutions have been used for washing the seeds after treatment and for maintaining the water level during after-ripening.

The preferred solution was the local tap water, which after sterilization showed a considerable deposit of calcium salts and had a pH of 8.5. The other, tried from time to time, was the nutrient solution previously described, which had a $\mathrm{pH}$ of 5.6.

In three experiments, cultures grown from seeds after-ripened in the two solutions were compared. No difference was noted in two trials, but in the third, superior cultures grew from the seeds after-ripened in the alkaline solution.

In one series, different flasks of seeds were after-ripened in the alkaline or acid soaking solutions. The radicles of the seeds emerged earlier in the alkaline solution than in the acid solution. A few weeks later, after the radicles had grown a few millimeters, the seeds after-ripened under the two conditions did not differ noticeably.

The tap water was equal, if not superior, to the nutrient solution and had the advantage of convenience. 
After-ripening Temperature. A uniform after-ripening temperature was not available throughout this work. For the most part, seeds were afterripened at $36^{\circ} \mathrm{F}$. In many instances, however, it became necessary to change the temperature of the after-ripening room or to move seeds to other cold rooms in order to facilitate other work.

At times seeds have suffered temperature changes ranging from $32^{\circ} \mathrm{F}$ to $45^{\circ} \mathrm{F}$. No noticeable ill effects have occurred from such changes.

Moisture Requirements During After-ripening. Maintenance of the proper moisture content of seeds after-ripened in the absence of a stratification medium is difficult, if not impossible, unless some free water is left in the flask. Otherwise, the seeds dry quickly, necessitating almost daily additions of a few drops of water.

There seems to be a widespread belief that peach seeds are likely to rot during after-ripening in the presence of too much water. With "sterile" peach seeds, this did not prove true. If there were no organisms present that could grow on or attack them, the seeds did not rot because of an excess of water. Many seeds have, in fact, been successfully after-ripened while completely submerged, though for reasons to be discussed presently, this practice is not considered desirable.

The standard practice in this work was to leave just enough water in the after-ripening flasks approximately to half-submerge the seeds in the bottom layer. Sterile water was added from time to time before evaporation was complete. As long as the flask contained any free water, all the seeds, even those in the top layer, remained covered with a film of water. With this procedure, the seeds began to grow during the after-ripening period.

The following was typical of the behavior of nonsubmerged seeds during after-ripening.

At about 60 days, a few seed coats had split; at 70 days, some radicles had begun to emerge ; at 85 days, about 50 per cent of the radicles were showing; at 100 days, the longest radicles were about $4 \mathrm{~mm}$ long; and at 120 to 130 days, the most active seeds had radicles up to $1.5 \mathrm{~cm}$ in length. After they had reached a length of $2 \mathrm{~cm}$, or rarely $3 \mathrm{~cm}$-at approximately 140 daysthe radicles elongated very little. By 230 days, several short lateral roots, 2 to $3 \mathrm{~mm}$ in length, were usually growing from the radicle. Also at that time, the plumules, which could first be seen through the split seed coats at some time between 130 and 150 days, had reached a length of 1.0 to $1.5 \mathrm{~cm}$.

When seeds were after-ripened while submerged, there was a retardation of the growth reactions noted above roughly proportional to the depth of submergence. If only sufficient water was used to cover the highest seeds in the flask, there was a noticeable gradient from top to bottom. Those just under the surface of the water initiated growth at about the same time as the nonsubmerged seeds, but those on the bottom were retarded, and the growth of the radicles was much slower.

One group of seeds was after-ripened while deeply submerged. The 125 ce after-ripening flasks were filled to the necks with water. After 154 days in the after-ripening room, the seeds were covered by about $4 \mathrm{~cm}$ of water. None of the seed coats had split; no radicles had emerged. Two of these flasks of seeds were cultured and grew fairly well. In fact, they grew better than 


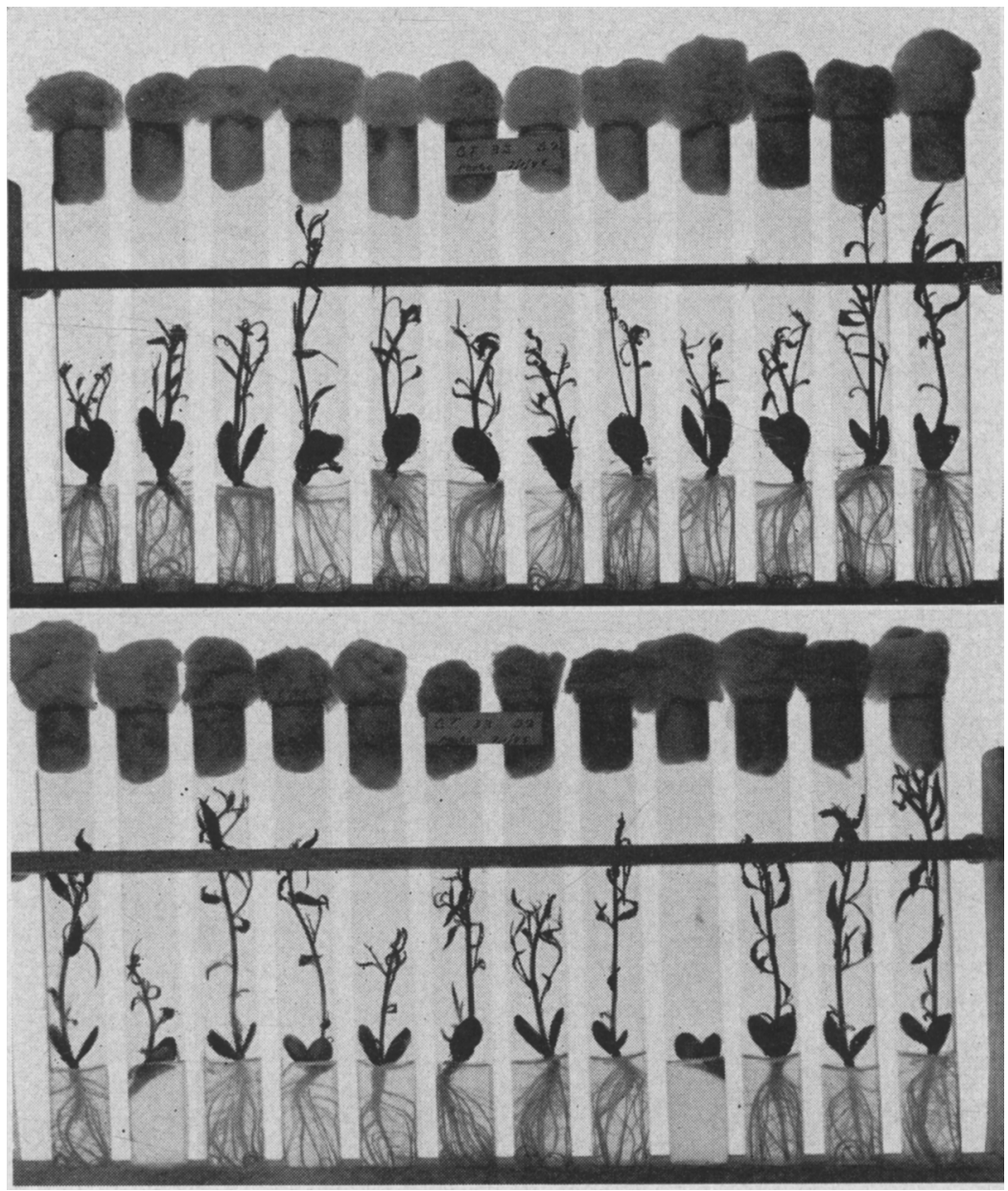

Fig. 6. Comparison of cultures from seeds after-ripened while submerged and from seed not submerged. Fifteen-day-old cultures from seeds after-ripened 154 days. (Top) Check, normal after-ripening procedure. Radicles $2-2.5 \mathrm{~cm}$ long at time of culturing. (Bottom) Grown from seeds deeply submerged during afterripening, they had not germinated at time of culturing.

the checks from nonsubmerged seeds, which showed severe tip dieback, presumably because of the excessively long after-ripening period (fig. 6). At the end of the 2-week culture period, some plants from the submerged seeds had an appearance suggestive of the dwarfing symptoms of Flemion (1934) and Tukey (1933). The pronounced rosetting reported by these authors did not occur in the cultures here described. Near the end of the culture period, however, small, curled, chlorotic leaves appeared at the growing points in some cultures grown from seeds after-ripened for short periods. This type of growth was thought to be an early indication of dwarfing and is the symptom to which reference is made when dwarfing is mentioned. 
Of these deeply submerged seeds, two flasks were observed in the afterripening room for more than a year. After 210 days, a few radicles had pushed through the seed coats. They developed no further and by the end of the year were discolored and looked dead.

Most of the seeds that were after-ripened while submerged grew well. With the exception noted above, they did not, however, make as satisfactory growth as the nonsubmerged seeds used as checks. Submergence retards not only the growth responses that accompany after-ripening but presumably also the rate of the after-ripening process. For this reason, it is not desirable to use such seeds for test purposes.

After-ripening Period. Though cultures from seeds after-ripened less than 80 days started well, the dwarfing characteristics previously mentioned occurred in many sets.

For the longer periods, up to approximately 150 days, the vigor with which the plumules grew during the first week in culture seemed proportional to the length of the after-ripening period. After 170 days, the tips of the radicles seemed to lose their ability to grow, though vigorous branch roots were put out. Plumules grew vigorously for a few days, but practically all died back at the tips. At 200 days of after-ripening, some seeds had died. Of those that grew, vigorous branch roots arose from the radicles, but the plumules developed poorly. After 240 days, the potential for growth had been largely lost, though about half the cotyledons showed greening in light.

Delay between Removal from the Cold Room and Culturing. Seeds brought from the cold room and allowed to remain at room temperature in the after-ripening flask sometimes grew rapidly for a few days. At other times, however, the radicle lengthened somewhat during the first 24 hours and thereafter remained static.

Ten pairs of culture sets were compared. One set of each pair was cultured shortly after removal from the cold room and the other after standing for 24 hours at room temperature in the after-ripening flask. In only one case did the seeds cultured after a 24-hour delay produce as good growth as those cultured soon after removal from the cold room.

Selection of Seeds for Culturing. Plump seeds of the Lovell variety rarely failed to germinate when after-ripened in "sterile" condition. A few, however, showed a weak potential for growth. In order to achieve uniformity in the cultures, seeds were selected for comparable growth of the radicle during the after-ripening process. It is thought that such selection may have eliminated at least a part of the poor growers.

Removal of the Seed Coats. Seeds cultured without removal of the seed coats suffered considerable injury as the cotyledons attempted to separate. Except at the point where the seed coat had been ruptured by the emergence of the radicle, the cotyledons were held together. As they attempted to open, they frequently tore themselves from the radicle or split it lengthwise.

In a single experiment, seed coats were cut around the major circumference along the line separating the cotyledons, thus allowing the cotyledons to separate. Though this incision prevented destruction of the seeds, these cultures had less vigor than those from seeds with the seed coats previously removed. 
Composition of the Medium. Several plant-culture solutions, other than the standard one previously described, gave satisfactory results. In fact, any reasonable plant-culture solution seemed to be satisfactory. The most important factor to be observed in preparation of the medium seemed to be accurate control of the agar concentration. Attention is again called to the previously cited reference to Tukey (1944).

Age of the Medium. The usual practice has been to use the medium within a day or two after preparation, though on several occasions cultures were grown in tubes of media prepared from 5 to 10 days before use. On most occasions, cultures have grown as well in old media as they have in fresh. If, however, the medium had softened on standing, the cultures were adversely affected.

Illumination. In the early experiments, little attention was paid to illumination. Later, cultures were grown on a poorly illuminated bench in the laboratory for the first week and were then transferred to the greenhouse for the remaining week of the usual 14-day culture period.

Cultures grown under this system were compared with those illuminated for about 10 hours each day during the first week of growth in the laboratory and then moved to the greenhouse. Illumination was from a mixture of fluorescent lights with a color temperature of approximately $4500^{\circ} \mathrm{K}$ and with an intensity of approximately 400 foot-candles. Figures 7 and 8 show that those cultures illuminated during the first week were superior.

Recently cultures have been grown for the entire culture period under $4500^{\circ} \mathrm{K}$ fluorescent lights at approximately the 400 -foot-candle-intensity level. A 14-hour-day has been used. From the standpoint of illumination, this condition has been satisfactory but, because of the closely placed lamps, has produced objectionably high temperatures.

Temperature. At no time has a means been available for controlling the temperature under which cultures were grown. Temperatures in the greenhouse varied between $65^{\circ}$ and $110^{\circ} \mathrm{F}$ and in the laboratory from $70^{\circ}$ to $95^{\circ} \mathrm{F}$. Apparently, uniformity and vigor of the cultures have been reduced by temperatures above $90^{\circ} \mathrm{F}$.

\section{GROWTH DISORDERS}

Tip Dieback. Tip dieback of the plumules in the cultures has been a source of considerable difficulty throughout the work. No precise study of the trouble has been attempted. At present it is thought that extended afterripening periods may be a contributing factor.

Tip dieback has seldom been observed in seedlings grown in sand in the greenhouse, though in one instance it was observed in a few seedlings grown from seeds after-ripened for more than 170 days. Seeds used for greenhouse plantings have been after-ripened by the same method as those used for sterile cultures.

In general, tip dieback seems to be most prevalent in cultures grown from seeds after-ripened for periods of 130 to 150 days and over. It has also been observed, however, in cultures grown from seeds after-ripened for only 70 days.

No relation has been discovered between the disorder and the source of either the distilled water or the agar used to prepare the culture medium. 


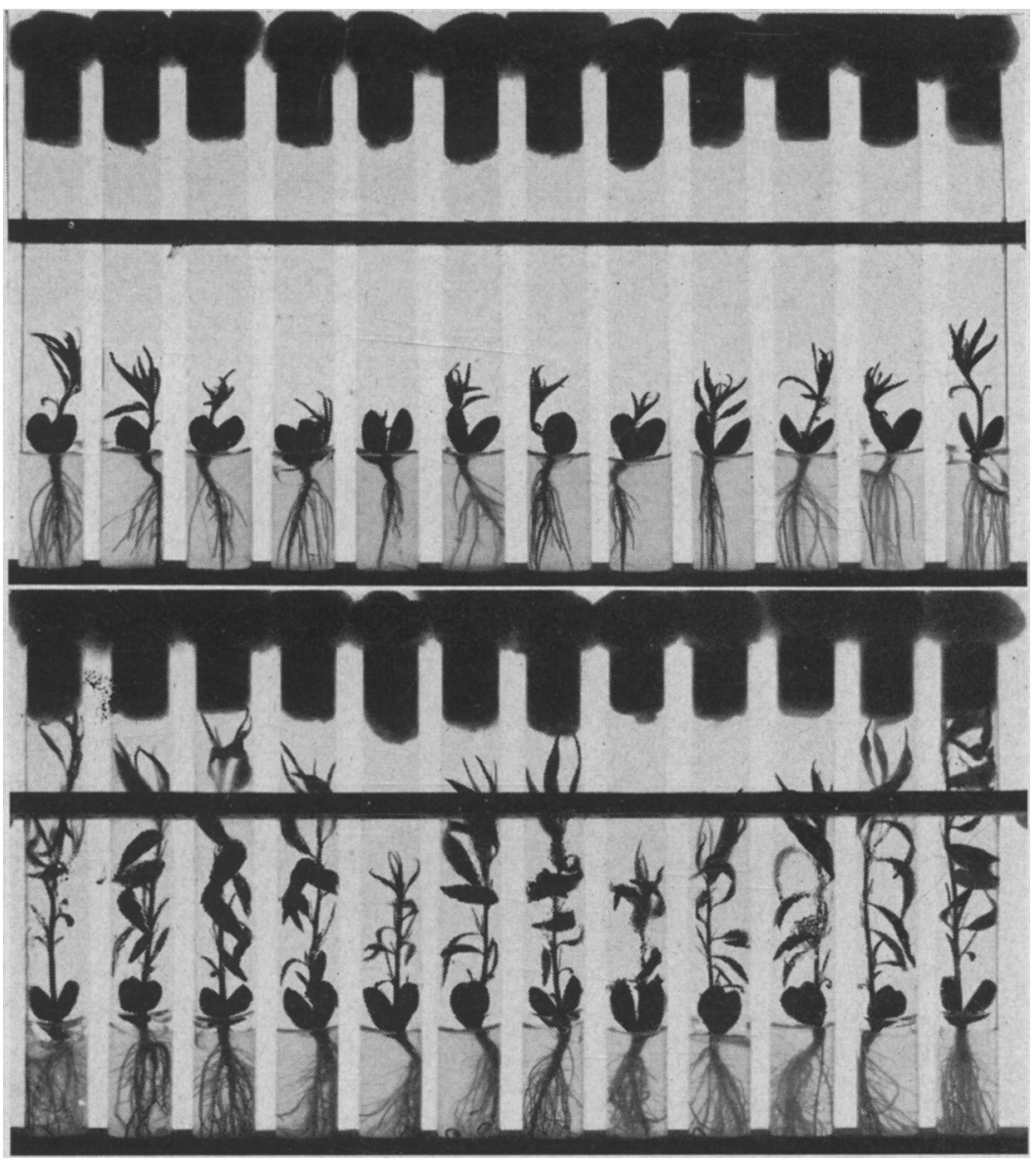

Fig. 7. Cultures illuminated during entire culture period. From seeds afterripened 118 days. (Top) Development at 7 days. (Bottom) Development at 14 days. Compare with figure 8.

The influence of the level of illumination under which cultures were grown (figures 7 and 8 ) was tested in one experiment. In this instance, the tipdieback symptom did not occur in any of the cultures at either the high or low level of illumination. As soon as the tip of the plumule died, one or more shoots arose from it. These shoots sometimes grew without further incident but in other cases soon died back at the tip also. An example of the disorder is shown in figure 9 .

"Curly Root." A growth disorder that occurred from time to time, but too infrequently to be a serious problem, was the "curly root" symptom, illustrated in figure 10. Poor plumule growth accompanied this abnormal root development. The roots were noticeably thickened and had a marked tendency to form vertical loops as they grew down through the agar. They branched profusely and formed a tangled mass of thickened, interlaced roots which, in some cases, grew too poorly to reach the bottom of the tube. 


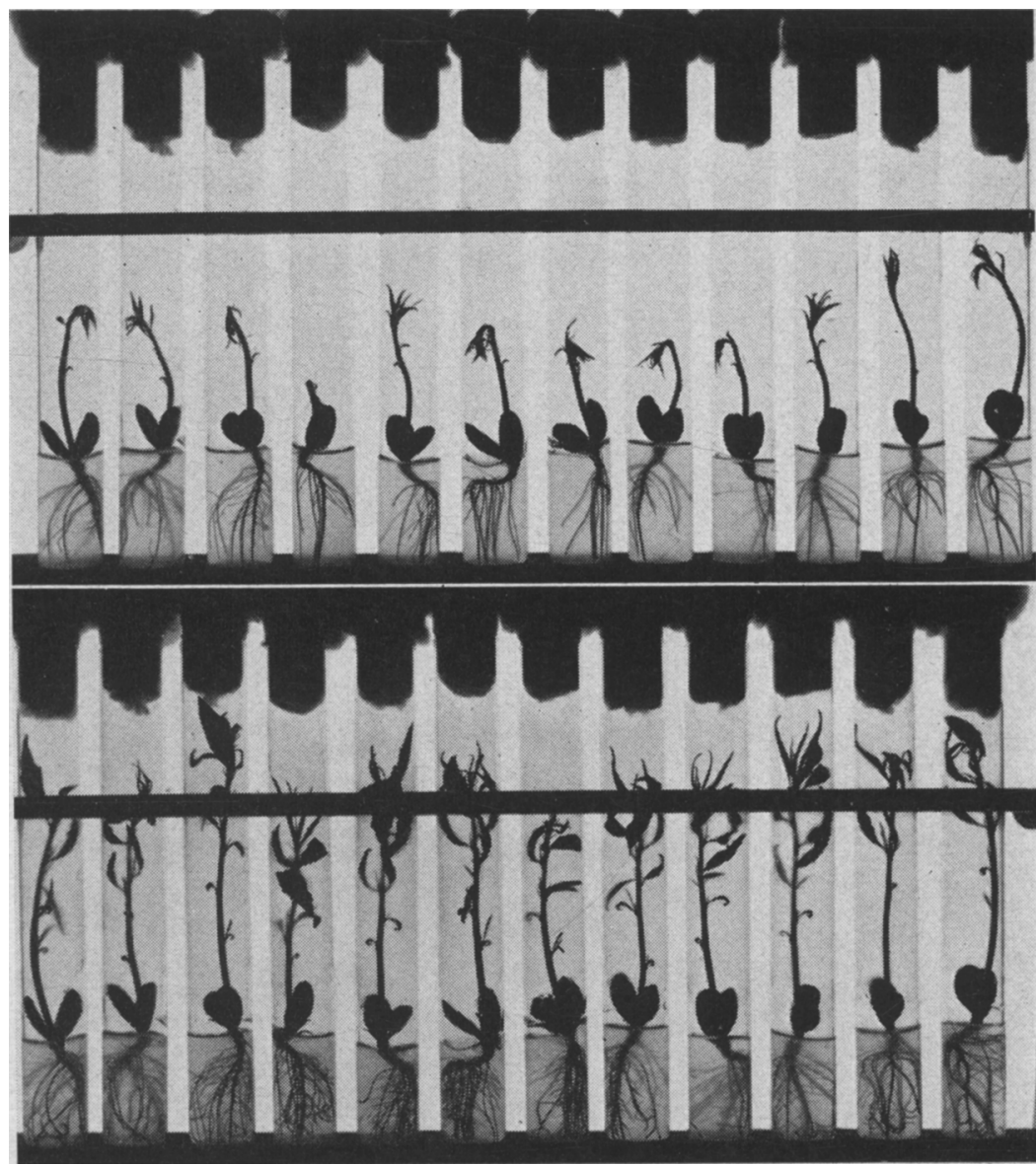

Fig. 8. Cultures grown at a low level of illumination during the first week of growth but illuminated during the second week of growth. (Top) Development at 7 days. (Bottom) Development at 14 days. Compare with figure 7 .

This phenomenon is apparently the result of an injury to the embryo at some time before culturing. In one experiment it was readily produced in 100 per cent of the cultures. This was done by allowing seeds after-ripened for less than 100 days to remain in the after-ripening flasks for 24 hours at room temperature before culturing. Later trials using the same procedure with seeds after-ripened for 130 days or more have failed to produce the symptom in more than a small percentage of the cultures. 


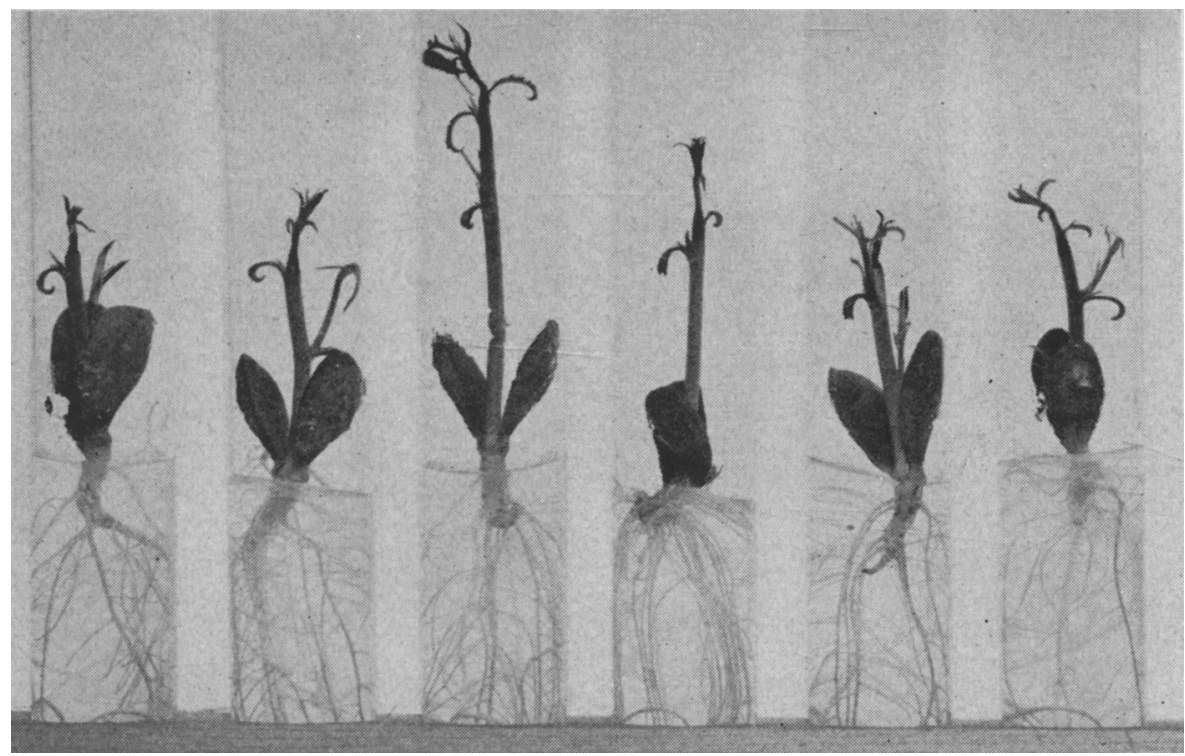

Fig. 9. Severe tip dieback. Fourteen-day-old cultures from seeds after-ripened 172 days. Plumules had reached the development shown by the end of the first 7 days, at which time constriction of the tip was evident but necrosis had not yet set in.

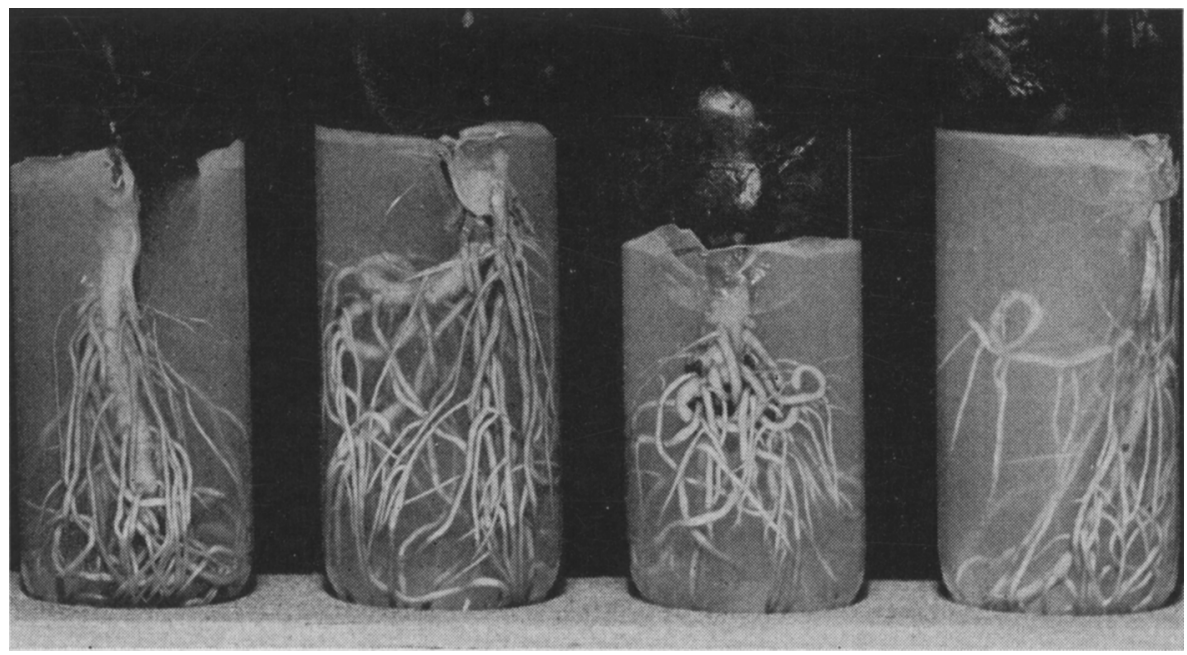

Fig. 10. "Curly root." Thirty-day-old cultures from seeds after-ripened 80 days. Compare with normal roots in other illustrations. 


\section{PROPOSED STANDARDIZED TECHNIQUE FOR CULTURE OF PEACH EMBRYOS}

On the basis of the observations recorded, the following points are suggested as a basis for standardizing the technique for growing "sterile" peach-embryo cultures to be used for bio-testing.

1. Use Merthiolate-alcohol-treated and aseptically after-ripened seeds.

2. Keep seeds wet but not submerged during after-ripening.

3. Use a washing and soaking solution with a slightly basic reaction.

4. After-ripen seeds at $36^{\circ} \mathrm{F}$.

5. Use seeds after-ripened for 100 to 110 days.

6. Culture seeds within 1 hour after removal from cold room.

7. Use only those seeds that have developed a vigorous radicle during the after-ripening period.

8. Remove seed coats before culturing.

9. Employ the modified Hoagland solution, previously described, as a basis for the culture medium. Control agar concentration accurately at 6.5 gms per liter.

10. Use culture tubes $25 \times 200 \mathrm{~mm}$ containing $50 \mathrm{~mm}$ of agar.

11. Grow cultures under controlled temperature.

12. Illuminate cultures with $4500^{\circ} \mathrm{K}$ fluorescent lights 10 to 14 hours a day.

13. Screen cultures for contaminants at conclusion of tests by means of yeast-extract broth.

\section{ACKNOWLEDGMENT}

The author gratefully acknowledges the help of Professors C. S. Mudge and M. P. Starr, who gave valuable advice on bacteriological procedures, and of Mr. Manley Mandel, who checked for bacterial contamination much of the material described. 


\section{LITERATURE CITED}

Flemion, Florence.

1934. Dwarf seedlings from non-after-ripened embryos of peach, apple and hawthorn. Boyce Thompson Inst. for Plant Research, Contrib. 6:205-9.

HAUT, I. C., and F. E. GARDNER.

1934. The influence of pulp disintegration upon the viability of peach seeds. Amer. Soc. Hort. Sci. Proc. $32: 323-27$.

Hoagland, D. R., and D. I. Arnon.

1938. The water-culture method for growing plants without soil. California Agr. Exp. Sta. Cir. 347:1-37.

LaRue, CARL D.

1937. The use of bromine in the sterilization of fruits and seeds. Science $85: 319$.

Proebsting, E. L., and A. E. Gilmore.

1941. The relation of peach root toxicity to the re-establishing of peach orchards. Amer. Soc. Hort. Sci. Proc. $38: 21-26$.

Scoto, H. D., J. G. Waugh, and F. P. Cullinan.

1942. An injurious effect of peach juice on germination of the seed. Amer. Soc. Hort. Sci. Proc. $40: 283-85$.

TUKeY, H. B.

1933. Artificial culture of sweet cherry embryos. Jour. Heredity 24:7-12.

1934. Artificial culture methods for isolated embryos of deciduous fruits. Amer. Soc. Hort. Sci. Proc. $32: 313-22$.

1944. The excised-embryo method of testing the germinability of fruit tree seed with particular reference to peach seed. Amer. Soc. Hort. Sci. Proc. 45:211-19.

White, PhILIP R.

1943. A handbook of plant tissue culture. p. 277. The Jacques Cattell Press. Lancaster, Pennsylvania.

WiLson, JAMEs K.

1915. Calcium hypochlorite as a seed sterilizer. Amer. Jour. Bot. 2:420-27. 
The journal Hilgardia is published at irregular intervals, in volumes of about 600 pages. The number of issues per volume varies.

Subscriptions are not sold. The periodical is sent as published only to libraries, or to institutions in foreign countries having publications to offer in exchange.

You may obtain a single copy of any issue free, as long as the supply lasts; please request by volume and issue number from:

\section{Publications Office \\ College of Agriculture \\ Berkeley 4, California}

The limit to nonresidents of California is 10 separate issues on a single order. A list of the issues still available will be sent on request.

In order that the information in our publications may be more intelligible it is sometimes necessary to use trade names of products or equipment rather than complicated descriptive or chemical identifications. In so doing it is unavoidable in some cases that similar products which are on the market under other trade names may not be cited. No endorsement of named products is intended nor is criticism implied of similar products which are not mentioned. 